\title{
Philosophiques
}

\section{Livres reçus (automne 2003)}

Volume 30, numéro 2, automne 2003

URI : https://id.erudit.org/iderudit/008666ar

DOI : https://doi.org/10.7202/008666ar

Aller au sommaire du numéro

Éditeur(s)

Société de philosophie du Québec

ISSN

0316-2923 (imprimé)

1492-1391 (numérique)

Découvrir la revue

Citer ce document

(2003). Livres reçus (automne 2003). Philosophiques, 30(2), 489-490.

https://doi.org/10.7202/008666ar

Ce document est protégé par la loi sur le droit d'auteur. L'utilisation des services d'Érudit (y compris la reproduction) est assujettie à sa politique d'utilisation que vous pouvez consulter en ligne.

https://apropos.erudit.org/fr/usagers/politique-dutilisation/
Cet article est diffusé et préservé par Érudit.

Érudit est un consortium interuniversitaire sans but lucratif composé de l’Université de Montréal, l'Université Laval et l'Université du Québec à Montréal. Il a pour mission la promotion et la valorisation de la recherche. https://www.erudit.org/fr/ 


\section{Livres reçus (automne 2003)}

Andler, Daniel, Fagot-Largeault, Anne, Saint-Sernin, Bertrand, Philosophie des sciences, vol. I et II, Paris, Gallimard, 2002, 1334 pages.

Cantin, Serge, Nous voilà rendus au sol. Essai sur le désenchantement du monde, Montréal, Editions Bellarmin (collection: L'essentiel), 2003, 207 pages.

Dagenais, Daniel (dir.), Hannah Arendt, le totalitarisme et le monde contemporain, Québec, Presses de l'Université Laval, 2003, 611 pages.

Faivre, Antoine, Theosophy, Imagination, Tradition. Studies in Western Esotericism, traduit du français par Christine Rhone, Albany, State University of New York Press, 2000, 269 pages.

Fisette, Denis (ed.), Husserl's Logical Investigations Reconsidered, Dordrecht, Kluwer (collection Contributions to Phenomenology), 2003, 235 p.

Fisette, Denis, Lapointe, Sandra (dir.), Aux origines de la phénoménologie. Husserl et le contexte des Recherches Logiques, Paris et Québec, Vrin et Presses de l'Université Laval (collection: Zêtêsis), 2003, 311 pages.

Gauthier, Yvon, Internal Logic: Foundations of Mathematics from Kronecker to Hilbert, Dordrecht, Kluwer (collection: Synthese Library), 2002, 248 pages.

Knee, Philip, La parole incertaine: Montaigne en dialogue, Québec, Presses de l'Université Laval (Les collections de la République des Lettres), 2003, 228 pages.

Künne, Wolfgang, Conceptions of Truth, Oxford, Clarendon Press, 2003, 493 pages.

Moreau, Pierre-François (dir.), Lectures de Michel Foucault, 3. Sur les Dits et écrits, Lyon, ÉNS éditions, 2003, 101 pages.

Narbonne, Jean-Marc, La métaphysique de Plotin. Suivi de Henôsis et Ereignis: remarques sur une interprétation heidegérienne de l'Un plotinien, Paris, Vrin, 2001, 180 pages.

Pouivet, Roger, L'œuvre d'art à l'âge de sa mondialisation. Un essai d'ontologie de l'art de masse, Bruxelles, La Lettre volée (collection: Essais), 2003, 113 p.

Raymond, Jean-François de, Descartes et le Nouveau Monde. Le cheminement du cartésianisme au Canada XVII $-X X^{e}$ siècles, Paris et Québec, Vrin et Presses de l'Université Laval (collection: Zêtêsis), 333 pages.

Russell, Bertrand, Le pouvoir, trad. de l'anglais par Michel Parmentier, Québec, Les Presses de l'Université Laval et les Editions Syllepse (collection: Zêtêsis), 2003, 230 pages.

Sangalli, Arturo, Éloge du flou. Aux frontières des mathématiques et del'intelligence artificielle, Montréal, Presses de l'Université de Montréal, 2001, 206 pages.

Sider, Theodore, Four Dimensionalism. An Ontology of Persistence and Time, Oxford, Clarendon Press, 2003(2001), 255 pages.

Silva, Emmanuel da (dir.), Lectures de Michel Foucault, 2. Foucault et la philosophie, Lyon, ÉNS éditions, 2003, 134 pages. 
Outre les ouvrages qui apparaissent dans cette liste, la rédaction de Philosophiques peut obtenir, pour fin de compte rendu ou d'étude critique, la plupart des livres parus récemment.

Les personnes désireuses de faire un compte rendu sont priées de s'adresser à :

Jimmy Plourde

Département de philosophie

Université du Québec à Montréal

C.P. 8888 , Succ. Centre-ville

Montréal, H3C 3P8

Courriel : jimmy.plourde@uqam.ca 